\title{
Short communication: Summer on-farm environmental condition assessments in Québec tiestall farms and adaptation of temperature- humidity index calculated with local meteorological data
}

\author{
V. Ouellet, A. L. Bellavance, S. Fournel, and É. Charbonneau* \\ Département des Sciences Animales, Université Laval, Québec, QC, Canada G1V 0A6
}

\begin{abstract}
Temperature-humidity index (THI) calculation following the equation developed by the National Research Council (A Guide to Environmental Research on Animals, 1971) requires ambient temperature (AT) and relative humidity (RH). Those data are widely and readily available at local meteorological stations. However, studies showed that using average $\mathrm{AT}$ and $\mathrm{RH}$ retrieved from the closest stations is not appropriate for estimating on-farm conditions. The present objectives were (1) to study summer on-farm environmental conditions, (2) to explore the relationship between summer THI calculated with on-farm data and summer THI calculated with local weather station data, and (3) to verify whether THI calculated with summer meteorological station data could be adapted to better represent summer on-farm conditions. Six tiestall dairy farms located in 2 regions of the province of Québec [Eastern Québec (EQ) and Southwestern Québec (SWQ)] were enrolled in this study. Within-barn conditions were monitored using 3 remote data loggers from August 2016 through August 2017. Two loggers were installed inside at varying distances relative to the ventilation inlet (L1: closest to inlet; L2: farthest from inlet) and a third was installed just outside of the barn (L3). Values retrieved from each logger and the closest local meteorological station were used to calculate daily THI according to the National Research Council formula and were ultimately compared. Our results showed that THI varied within the barn depending on the proximity relative to the inlet because THI measured by L1 was lower than THI measured by L2 in both regions. Moreover, our results showed that in both regions AT measured onfarm was consistently higher than AT measured at the weather station. The opposite was observed with $\mathrm{RH}$, as it was significantly lower on-farm in EQ and numerically lower in SWQ compared with RH extracted from
\end{abstract}

Received December 12, 2018.

Accepted April 4, 2019.

*Corresponding author: edith.charbonneau@fsaa.ulaval.ca weather stations. Overall, this led to THI being lower by 4.6 and 3.7 units at the weather stations compared with within-barn conditions for EQ and SWQ farms, respectively. Hence, using local meteorological station data to estimate on-farm conditions would lead to an underestimation of heat stress level in dairy cows. Adapting THI calculations by including daily maximum $\mathrm{AT}$ and minimum $\mathrm{RH}$ retrieved from the local weather station instead of their average counterparts led to a better estimation of within-barn conditions. However, the difference between THI measured on-farm and the adapted THI calculated with weather station data remained significant. Although the adaption made to THI allowed for a closer relation to on-farm conditions, THI calculated with weather station data should only be used to assess heat stress level in dairy cows when heat stress thresholds are adapted for such data.

Key words: heat stress, temperature-humidity index, dairy barn

\section{Short Communication}

During summer months, as ambient temperature (AT) and relative humidity $(\mathbf{R H})$ increase inside the barn, dairy cows' heat dissipation ability is often challenged. Environmental conditions coupled with the high metabolic heat produced by the animal may cause a heat surplus and the cow to enter a state of heat stress. This condition has been reported to have profound effects on dairy cows' health, well-being, and performance (West et al., 2003), making heat stress a costly issue for the dairy industry. Heat stress has received a lot of attention in past years because its effects are expected to exacerbate over time considering higher temperatures arising from global climate change and because increased milk yield is related to a decrease in health tolerance (Berman et al., 1985). In addition, heat stress is expected to become an issue in areas characterized by cooler annual average temperature (Key et al., 2014).

To estimate the magnitude of heat stress in dairy cows, a bioclimatic metric that combines the effects of 
AT and RH named temperature-humidity index (THI) is commonly used. Although the index was not developed with cow data, many studies have demonstrated that it is related to rectal temperatures of cattle exposed to heat stress (Dikmen and Hansen, 2009) and is predictive of milk yield (Bohmanova et al., 2007). The popularity of the index is mainly related to its convenience because it can be easily calculated as it requires only the widely and rapidly available AT and RH. Furthermore, it is a noninvasive way to assess heat stress in animals. Heat stress thresholds above which dairy cow performance is compromised have been identified with THI and may vary among production systems, traits, climate, cow productivity, THI formula, and weather data source (Wang et al., 2018).

Weather data retrieved from local meteorological stations are convenient for calculating THI because they are widely and readily available. Moreover, the use of public weather station data in THI calculations as a surrogate for on-farm THI has allowed researchers to study the effects of heat on a larger number of animals. However, it recently has been shown that daily THI measured within the barn is consistently higher than that of the closest meteorological station in both freestall and tiestall barns in temperate climates (Schüller et al., 2013; Shock et al., 2016). This means that THI calculated with weather station data cannot accurately assess heat level when heat stress thresholds identified with on-farm data are used. Finding a proper way to adapt local weather station data to better represent on-farm conditions would be a cost-effective way to accurately and rapidly assess heat stress level in dairy cows to make appropriate adjustments in a timely manner.

The current study had 3 objectives. The first was to study on-farm summer environmental conditions. The second was to compare THI measured during summer months with on-farm data to THI measured with data retrieved from the closest weather station. Finally, the third was to verify whether data retrieved from meteorological stations can be adapted in a THI formula to better represent on-farm conditions.

The study was conducted from August 2016 through August 2017 on 6 dairy farms, each recruited by a local representative. Before the beginning of the study, all producers signed a consent form allowing our team to install data loggers and to retrieve and use their data. The farms were all located in the province of Québec; 3 were located in Eastern Québec (EQ), and 3 were located in Southwestern Québec (SWQ). These farms represent a convenience sample and were selected based on their importance to the provincial dairy sector. Farms located in EQ had an average $( \pm \mathrm{SD})$ of 62.3 \pm 5.1 lactating cows, whereas farms located in SWQ had an average $( \pm \mathrm{SD})$ of $94.3 \pm 10.5$ lactating cows. In all farms, cows were kept in closed-sided tiestall barns throughout the year and thus had no pasture access. Ventilation in all farms was ensured by a hybrid ventilation system (tunnel ventilation during summer and natural ventilation during winter) designed to achieve 40 to 60 air changes per hour and to reach an air speed at animal level of about $2.5 \mathrm{~m} / \mathrm{s}$ during summer months. No heat stress abatement strategy was used on farms.

On-farm AT $\left({ }^{\circ} \mathrm{C}\right)$ and $\mathrm{RH}(\%)$ were directly recorded using a Hobo U23-01 Pro V2 Temperature/RH data logger (Onset Computer Corp., Bourne, MA) at 15min intervals. Three data loggers were installed on each farm. Two loggers were placed inside the barn. Logger 1 (L1) was secured on the barn ceiling about $1 \mathrm{~m}$ above the cows and close to the ventilation inlet. Logger 2 (L2) was positioned farther away from inlets, where air speed at cow level measured by an anemometer (LM81AM Compact Vane Anemometer, Reed Instruments, Wilmington, NC) was slower. A third logger (L3) was placed just outside of the barn under a protective device blocking solar radiation and precipitations. Ambient temperature and $\mathrm{RH}$ were offloaded from loggers each month by a local representative. Raw data were then downloaded as a comma-separated variable file and converted into hourly readings by taking the average value of four 15-min readings. Finally, hourly $\mathrm{AT}$ and $\mathrm{RH}$ values were converted into daily values by averaging 24 readings per calendar day.

Environmental data were extracted from local meteorological stations. The choice of meteorological stations was based on the availability of both AT and $\mathrm{RH}$ and on their relative distance to the farms. The geographic distance between each recruited farm and the stations in the vicinity was determined using Google Map Distance Calculator (http://www.daftlogic.com/projects -googlemaps-distance-calculator.htm) by entering the decimal degrees (latitude and longitude) of the herd and close meteorological stations. The meteorological station closest to each study farm was used as the station of comparison for that particular farm. Average farm distance relative to meteorological station was $($ mean $\pm \mathrm{SD}) 8.07 \pm 2.6 \mathrm{~km}$ in EQ and $35.3 \pm 7.8 \mathrm{~km}$ in SWQ.

Hourly AT and RH were downloaded for each meteorological station for the period August 1, 2016, through August 31, 2017, from the Government of Canada's official climate database (http://climate.weather.gc.ca/ ). Hourly data were then expressed as daily readings in 2 ways. In the first way, hourly data were converted into daily readings by averaging $24 \mathrm{AT}\left(\mathbf{A T}_{\mathrm{avg}}\right)$ and $\mathrm{RH}$ $\left(\mathbf{R H}_{\mathrm{avg}}\right)$ readings per calendar day. The second way involved extracting daily maximum $\mathrm{AT}\left(\mathbf{A} \mathbf{T}_{\max }\right)$ and the corresponding minimum $\mathrm{RH}\left(\mathbf{R H}_{\text {min }}\right)$ per calendar day. 
Mean daily $\mathrm{AT}_{\text {avg }}$ and $\mathrm{RH}_{\mathrm{avg}}$ offloaded from L1, L2, and L3 and retrieved from local weather stations were used to calculate THI following the equation of NRC (1971):

$$
\begin{aligned}
& \mathrm{THI}=\left(1.8 \times \mathrm{AT}_{\mathrm{avg}}+32\right)-\left[\left(0.55-0.0055 \times \mathrm{RH}_{\mathrm{avg}}\right)\right. \\
&\left.\times\left(1.8 \times \mathrm{AT}_{\mathrm{avg}}-26\right)\right],
\end{aligned}
$$

where $\mathrm{AT}_{\text {avg }}$ is the daily average $\mathrm{AT}\left({ }^{\circ} \mathrm{C}\right)$ and $\mathrm{RH}_{\text {avg }}$ is daily mean $\mathrm{RH}(\%)$.

Equation 1 was selected because it has been widely used in heat stress trials with different types of climates (Ravagnolo and Misztal, 2000; Schüller et al., 2013; Shock et al., 2016) and because most heat stress thresholds found in the literature were identified based on this equation. Moreover, in a study comparing the ability of 8 THI formulae to predict rectal temperatures in dairy cows, the authors reported that the formula developed by NRC (1971; Equation 1) exhibited the highest coefficient of determination (Dikmen and Hansen, 2009).

Considering the results of a previous study conducted on 50 dairy farms in Ontario, Canada (Shock et al., 2016), that indicated that on-farm AT is consistently higher and that on-farm RH is lower during most summer months compared with data extracted at meteorological stations, a modified version of THI $\left(\mathbf{T H I}_{\text {mod }}\right)$ was calculated with data retrieved from the local weather station during the summer months:

$$
\begin{aligned}
\mathrm{THI}_{\text {mod }} & =\left(1.8 \times \mathrm{AT}_{\max }+32\right)-[(0.55-0.0055 \\
& \left.\left.\times \mathrm{RH}_{\text {min }}\right) \times\left(1.8 \times \mathrm{AT}_{\text {max }}-26\right)\right],
\end{aligned}
$$

where $\mathrm{AT}_{\max }$ is the daily maximum $\mathrm{AT}\left({ }^{\circ} \mathrm{C}\right)$ and $\mathrm{RH}_{\min }$ is the daily minimum $\mathrm{RH}(\%)$. This adaptation was also previously tested in another context by Ravagnolo and Misztal (2000), who reported that $\mathrm{AT}_{\max }$ and $\mathrm{RH}_{\text {min }}$ are the most critical variables to quantify heat stress.

All data were analyzed using SAS 9.4 (SAS Institute Inc., Cary, NC). Dates with missing values for AT or $\mathrm{RH}$ were removed from the data set. The UNIVARIATE procedure was used to evaluate data normality. A normal distribution was confirmed using a Kolmogrov-Smirnov test $(P>0.05)$. Differences between data loggers and weather station data were assessed using the GLIMMIX procedure. Analyses were conducted separately for both regions (EQ, SWQ). Logger position was included as a fixed effect and farm was included as a random effect. Akaike information criterion was used to select the best covariance structure. Orthogonal contrasts were defined a priori and used to compare (1) L1 versus L2, (2) loggers inside the barn (L1, L2) versus the logger outside the barn (L3), and (3) inside loggers (L1, L2) versus local meteorological station data. Differences between loggers and local meteorological stations were declared significant when $P$-values were $<0.05$, and tendencies were noted when $0.05<P<0.10$. Subsequently, differences between THI from data loggers positioned inside the barn (L1, L2) and modified THI calculated with weather station data were assessed. Finally, simple correlations between THI measured with on-farm data and THI calculated with weather station data (Equations 1 and 2) were performed with the CORR procedure.

Mean AT measured on-farm varied during the summer months (June, July, and August) depending on the logger's position inside the barn (Table 1). Average AT measured by L1 was significantly lower $(P<0.05)$ than AT measured by L2. Relative humidity measured by L1 tended to be lower $(P<0.10)$ than RH measured by L2 in EQ farms, whereas it was significantly lower $(P<$ 0.05) in SWQ farms. Ultimately, this led to THI being significantly lower for L1 compared with L2 in both regions. This result was expected because L1 loggers were intentionally positioned closer to air inlets where air entering the barn is cooler. Therefore, our results suggest that within-barn environmental conditions may vary depending on the distance relative to ventilation inlet. This is of importance for dairy producers because certain groups of cows are more vulnerable to heat stress than others. Hence, dairy producers should pay attention when assigning stalls to their cows. In closedwall barns, high-producing pregnant cows should be placed closer to air inlets because they produced more metabolic heat than cows producing less milk, making them more susceptible to heat stress (Berman et al., 1985). In a tunnel-ventilated barn, cows closer to the air inlets benefit from higher convective heat losses through higher air speeds because air slows down as it passes through obstacles (e.g., housing equipment, animals) to get to the other end.

Mean AT measured inside the barn (L1, L2) was higher than AT measured outside the barn (L3) as shown in Table 1. Many factors (e.g., heat production from the cows, heat radiated from motors and lights) can explain the higher temperature measured inside compared with outside the barn (Collier et al., 2006). No significant difference $(P>0.05)$ was observed for RH between the inside and outside loggers in both regions, which can be indicative of proper on-farm ventilation. Ultimately, THI calculated with data retrieved from inside loggers $(\mathrm{L} 1, \mathrm{~L} 2)$ were significantly $(P>0.05)$ higher than THI calculated with data offloaded from the outside logger (L3).

Average AT measured at the closest local meteorological station was significantly lower than AT mea- 
sured by data loggers inside the barns (Table 1). On average $( \pm \mathrm{SD})$, AT was $3.22 \pm 0.14^{\circ} \mathrm{C}$ and $2.39 \pm$ $0.18^{\circ} \mathrm{C}$ higher in the barn compared with the closest meteorological station for EQ and SWQ farms, respectively. Other studies (Schüller et al., 2013; Shock et al., 2016) comparing environmental conditions recorded on-farm with environmental conditions recorded at the closest weather station obtained similar results.

In the present study, average $\mathrm{RH}$ measured inside the barn was significantly $(P<0.05)$ lower than $\mathrm{RH}$ measured at the weather station in EQ farms, whereas it was numerically $(P=0.99)$ lower in SWQ farms. The lower RH measured on-farm could indicate that air turnover inside the barns was sufficient to dissipate humidity produced by the cows. Also, the higher AT measured inside the barn could have led to lower $\mathrm{RH}$ due to air expansion under higher temperatures. Schüller et al. (2013) attained the same conclusion as ours, whereas Shock et al. (2016), who studied environmental conditions of 50 dairy barns (20 freestall, 30 tiestall), reported that $\mathrm{RH}$ was on aggregate higher in on-farm readings compared with weather station data. However, they also mentioned that this relationship was not consistent throughout the year. The authors reported that lower RH was measured inside the barn during June, August, and September. The discrepancies between results could be explained in part by different ventilation systems and housing types, the number of cows per farm, the distance between farms and weather stations, and possibly the lower number of farms enrolled in our study.

Overall, our results showed that THI measured inside the barn was significantly higher $(P>0.05)$ than THI calculated with data retrieved from the weather station. These results are in agreement with 2 other studies
(Schüller et al., 2013; Shock et al., 2016). Ultimately, we observed a mean $( \pm \mathrm{SD})$ daily difference of $4.6 \pm$ 2.3 and $3.7 \pm 2.6$ THI units between summer on-farm readings and local weather station data for EQ and SWQ farms, respectively. This closely agrees with results reported from another Canadian study conducted by Shock et al. (2016), who reported mean differences of 3 to 4 THI units.

Adaptations were made to Equation 1 to verify whether weather data could be adapted in THI calculations to better represent on-farm environmental conditions. Daily average AT and $\mathrm{RH}$ extracted from weather station data were replaced by daily $\mathrm{AT}_{\text {max }}$ and by daily $\mathrm{RH}_{\min }$ in Equation 2. Using $\mathrm{AT}_{\max }$ and $\mathrm{RH}_{\text {min }}$ led to the calculation of the daily maximum THI measured at the local weather station because higher AT is always accompanied by lower RH (De Rensis et al., 2015). This was performed to verify whether THI calculated in such a manner could better represent onfarm conditions and allow weather station data to be directly used as a surrogate to on-farm data.

Our results showed that $\mathrm{THI}_{\text {mod }}$ (Equation 2) was significantly higher $(P<0.05)$ than THI calculated with inside (L1, L2) on-farm readings following Equation 1 (Figure 1). However, our results suggested that $\mathrm{THI}_{\bmod }$ was more closely related to summer in-barn conditions compared with the usual calculated THI, as lower mean $( \pm \mathrm{SD})$ daily differences of $2.2 \pm 2.3$ and $1.9 \pm 2.5$ THI units were measured in EQ and SWQ farms, respectively. Simple correlations between summer average THI (Equation 1) calculated with onfarm data, THI (Equation 1) calculated with public weather station data, and $\mathrm{THI}_{\text {mod }}$ (Equation 2) calculated with weather station data are shown in Table 2. In both regions, the strongest correlation between

Table 1. Mean daily ambient temperature (AT), relative humidity (RH), and temperature-humidity index ${ }^{1}$ (THI) measured on 6 tiestall farms in 2 regions of the province of Québec and at the closest local weather station during summer ${ }^{2,3}$

\begin{tabular}{|c|c|c|c|c|c|c|c|c|c|}
\hline Item & \multicolumn{4}{|c|}{ Environmental data } & $\mathrm{SE}$ & \multicolumn{4}{|c|}{$P$-value } \\
\hline \multicolumn{10}{|c|}{ Eastern Québec } \\
\hline THI & 65.81 & 66.61 & 64.90 & 61.59 & 0.44 & $<0.001$ & $<0.010$ & $<0.0001$ & $<0.0001$ \\
\hline \multicolumn{10}{|c|}{ Southwestern Québec } \\
\hline $\mathrm{AT},{ }^{\circ} \mathrm{C}$ & 21.94 & 22.21 & 20.72 & 19.68 & 0.28 & $<0.0001$ & $<0.0001$ & $<0.0001$ & $<0.0001$ \\
\hline RH, \% & 70.38 & 70.85 & 73.44 & 71.92 & 1.08 & $<0.0010$ & $<0.0001$ & 0.110 & 0.990 \\
\hline THI & 69.30 & 69.76 & 67.59 & 65.99 & 0.46 & $<0.0001$ & $<0.0001$ & $<0.0001$ & $<0.0001$ \\
\hline
\end{tabular}

${ }^{1}$ Calculated as $\left(1.8 \times \mathrm{AT}_{\text {average }}+32\right)-\left[\left(0.55-0.0055 \times \mathrm{RH}_{\text {average }}\right) \times\left(1.8 \times \mathrm{AT}_{\text {average }}-26\right)\right]$.

${ }^{2}$ Summer defined as the months of June, July, and August.

${ }^{3} \mathrm{~L}=$ logger. 
Table 2. Simple correlations between average summer temperaturehumidity index (THI) calculated with data retrieved on-farm and with data extracted from the local weather station

\begin{tabular}{lcc}
\hline & $\begin{array}{c}\mathrm{THI}^{2} \\
\text { weather } \\
\text { station }\end{array}$ & $\begin{array}{c}\mathrm{THI}_{\mathrm{mod}}{ }^{3} \\
\text { weather } \\
\text { station }\end{array}$ \\
\hline Item & \\
Eastern Québec farms & $0.39^{* *}$ & $0.46^{* *}$ \\
THI L1 & $0.72^{* *}$ & $0.87^{* *}$ \\
THI L2 & $0.65^{* *}$ & $0.70^{* *}$ \\
THI L3 & $0.68^{* *}$ & $0.78^{* *}$ \\
THI inside (L1, L2) & $0.63^{* *}$ & $0.65^{* *}$ \\
Southwestern Québec farms & $0.65^{* *}$ & $0.76^{* *}$ \\
THI L1 & $0.62^{* *}$ & $0.63^{* *}$ \\
THI L2 & $0.64^{* *}$ & $0.70^{* *}$ \\
THI L3 &
\end{tabular}

${ }^{1} \mathrm{~L}=$ logger.

${ }^{2}$ Temperature-humidity index calculated as $\mathrm{THI}=(1.8 \times$ daily average AT +32$)-[(0.55-0.0055 \times$ daily average $\mathrm{RH}) \times(1.8 \times \mathrm{AT}-$ $26)] . \mathrm{AT}=$ ambient temperature; $\mathrm{RH}=$ relative humidity.

${ }^{3}$ Temperature-humidity index modified calculated as $\mathrm{THI}=(1.8 \times$ $\left.\mathrm{AT}_{\max }+32\right)-\left[\left(0.55-0.0055 \times \mathrm{RH}_{\min }\right) \times\left(1.8 \times \mathrm{AT}_{\max }-26\right)\right]$. $\mathrm{AT}_{\max }=$ maximum ambient temperature; $\mathrm{RH}_{\min }=$ minimum relative humidity.

${ }^{* *} P<0.0001$.

THI calculated with on-farm data and local weather station data was observed with $\mathrm{THI}_{\text {mod }}$. For EQ farms, correlations between on-farm THI and weather station THI calculated following Equation 1 varied from $\mathrm{r}=$
0.39 to $\mathrm{r}=0.68$, whereas they varied from $\mathrm{r}=0.46$ to $\mathrm{r}=0.87$ with $\mathrm{THI}_{\bmod }$. The highest correlation $(\mathrm{r}=$ 0.87) was observed between THI calculated with data offloaded from L2 and $\mathrm{THI}_{\bmod }$ calculated with weather station data. This result was expected because $\mathrm{THI}_{\bmod }$ overestimated on-farm conditions and because L2 was intentionally positioned in a less-ventilated area in the barn. In SWQ farms, correlations between on-farm THI and weather station THI calculated following Equation 1 varied from $r=0.62$ to $r=0.65$, whereas they varied from $\mathrm{r}=0.63$ to $\mathrm{r}=0.76$ with $\mathrm{THI}_{\mathrm{mod}}$. Again, the highest correlation $(r=0.76)$ was observed between summer THI calculated with data retrieved from $\mathrm{L} 2$ and $\mathrm{THI}_{\bmod }$ calculated with weather data. Ultimately, our results indicated that $\mathrm{THI}_{\text {mod }}$ better represented mean summer on-farm environmental conditions. Authors using this equation with weather station data should therefore identify heat stress thresholds adapted to such data.

Within-barn environmental conditions vary relative to the proximity to ventilation inlets. Dairy producers should attempt to place high-producing pregnant cows closer to ventilation because they are more vulnerable to heat stress. Using average local meteorological data to estimate average summer on-farm conditions led to an underestimation of heat stress level in dairy cows because AT was consistently lower and RH was numerically higher at weather station readings compared with

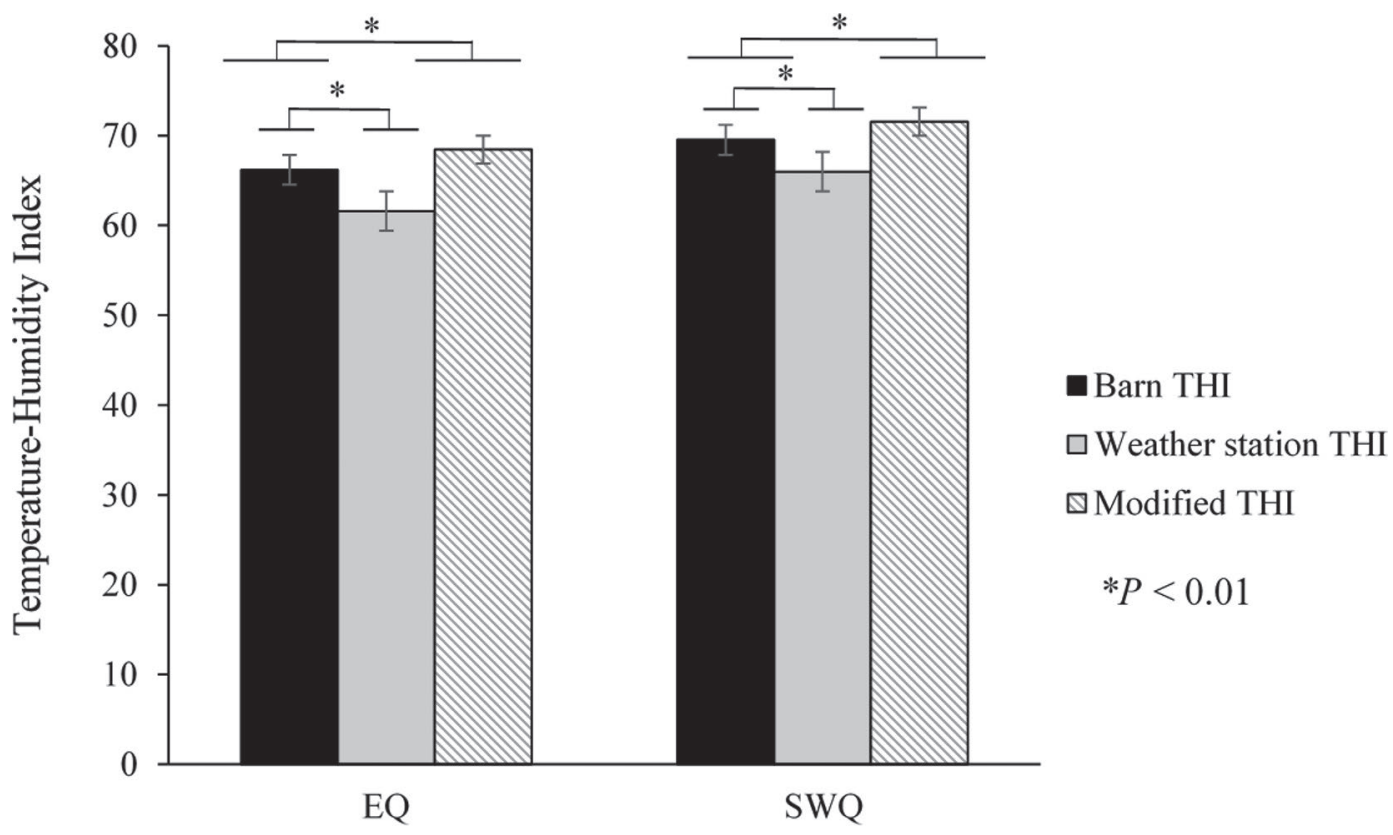

Figure 1. Comparison of temperature-humidity index (THI) calculated with average summer daily temperature and relative humidity retrieved from inside loggers (barn THI: black bars). THI calculated with average daily temperature and relative humidity extracted from the local weather station (gray bars), and THI calculated with average maximum daily temperature and minimum relative humidity retrieved from the local weather station (modified THI; striped bars) in 2 regions of the province of Québec (EQ = Eastern Québec; SWQ = Southwestern Québec) in Canada. Error bars represent SEM $=0.53$. 
on-farm readings. Although using a THI calculated with maximum $\mathrm{AT}$ and minimum $\mathrm{RH}$ retrieved from the local meteorological station better estimated average summer on-farm conditions compared with regular THI, it led to an overestimation of heat stress level. Therefore, heat stress thresholds have to be adapted to accurately assess heat stress level in dairy cows when data from weather stations are used in calculations.

\section{ACKNOWLEDGMENTS}

This study was supported by grants from the Direction régionale du Centre-du-Québec du Ministère de l'Agriculture, des Pêcheries et de l'Alimentation du Québec (MAPAQ), the Natural Sciences and Engineering Research Council of Canada (Canada), the Consortium on Regional Climatology and Adaptation to Climate Change Ouranos (Montreal, QC, Canada), the Fonds de Recherche Nature et Technologiqes Québec (Québec, QC, Canada), and Mitacs (Québec City, QC, Canada). The authors thank all the producers who participated in the study and Hugues Fiola and Gaëtan Bonneau of the Ministère de l'Agriculture, des Pêcheries et de l'Alimentation du Québec (Rimouski and StHyacinthe, QC, Canada) for their help recruiting the farms. Finally, the authors thank the administrative and research staff of the Centre de Recherche en Sciences Animales de Deschambault (Deschambault, QC, Canada).

\section{REFERENCES}

Berman, A., Y. Folman, M. Kaim, M. Mamen, Z. Herz, D. Wolfenson, A. Arieli, and Y. Graber. 1985. Upper critical temperatures and forced ventilation effects for high-yielding dairy cows in subtropical climate. J. Dairy Sci. 68:1488-1495.

Bohmanova, J., I. Misztal, and J. B. Cole. 2007. Temperature-humidity indices as indicators of milk production losses due to heat stress. J. Dairy Sci. 90:1947-1956.

Collier, R. J., G. E. Dahl, and M. J. VanBaale. 2006. Major advances associated with environmental effects on dairy cattle. J. Dairy Sci. 89:1244-1253.

De Rensis, F., I. Garcia-Ispierto, and F. Lopez-Gatis. 2015. Seasonal heat stress: Clinical implications and hormone treatments for the fertility of dairy cows. Theriogenology 84:659-666.

Dikmen, S., and P. J. Hansen. 2009. Is the temperature-humidity index the best indicator of heat stress in lactating dairy cows in a subtropical environment? J. Dairy Sci. 92:109-116.

Key, N., S. Sneeringer, and D. Marquardt. 2014. Climate change, heat stress, and U.S. dairy production. USDA Economic Research Report No. 175. USDA, Washington, DC.

NRC. 1971. A Guide to Environmental Research on Animals. Natl. Acad. Sci., Washington, DC.

Ravagnolo, O., and I. Misztal. 2000. Genetic component of heat stress in dairy cattle, parameter estimation. J. Dairy Sci. 83:2126-2130.

Schüller, L. K., O. Burfeind, and W. Heuwieser. 2013. Short communication: Comparison of ambient temperature, relative humidity, and temperature-humidity index between on-farm measurements and official meteorological data. J. Dairy Sci. 96:7731-7738.

Shock, D. A., S. J. Leblanc, K. E. Leslie, K. Hand, M. A. Godkin, J. B. Coe, and D. F. Kelton. 2016. Studying the relationship between on-farm environmental conditions and local meteorological station data during summer. J. Dairy Sci. 99:2169-2179.

Wang, X., B. S. Bjerg, C. Y. Choi, C. Zong, and G. Zang. 2018. A review and quantitative assessment of cattle-related thermal indices. J. Therm. Biol. 77:24-37.

West, J. W., B. G. Mullinix, and J. K. Bernard. 2003. Effects of hot, humid weather on milk temperature, dry matter intake, and milk yield of lactating dairy cows. J. Dairy Sci. 86:232-242. 